\title{
Protein Synthesis within Dendrites: Glycosylation of Newly Synthesized Proteins in Dendrites of Hippocampal Neurons in Culture
}

\author{
Enrique R. Torre and Oswald Steward \\ Department of Neuroscience, University of Virginia School of Medicine, Charlottesville, Virginia 22908
}

There is increasing evidence that certain mRNAs are present in dendrites and can be translated there. The present study uses two strategies to evaluate whether dendrites also possess the machinery for protein glycosylation. First, precursor labeling techniques were used in conjunction with autoradiography to visualize glycosyltransferase activities that are characteristic of the rough endoplasmic reticulum (RER) (mannose) or the Golgi apparatus (GA) (galactose and fucose) in dendrites that had been separated from their cell bodies and in intact neurons treated with brefeldin A or low temperature. Second, immunocytochemical techniques were used to define the subcellular distribution of proteins that are considered markers of the RER (ribophorin I) and GA (p58, $\alpha$-mannosidase II, galactosyltransferase, and TGN38/41). Autoradiographic analysis revealed that isolated dendrites incorporated sugar precursors in a tunicamycin-sensitive and protein synthesis-dependent manner. Moreover, when intact neurons were pulse-labeled with ${ }^{3} \mathrm{H}$-labeled sugars at low temperature or after treatment with brefeldin A, labeling was distributed over proximal and sometimes distal dendrites. Immunolabeling for RER markers was predominantly localized in cell bodies but extended for a considerable distance into dendrites of all neurons. Immunolabeling for GA markers was confined to the cell body in $\sim 70 \%$ of the neurons, but in $30 \%$ of the neurons, the staining extended into proximal and middle dendrites. These results indicate that the machinery for glycosylation extends well into dendrites in many neurons.

Key words: rough endoplasmic reticulum; Golgi apparatus; TGN; dendrites; glycosylation; hippocampal neurons; dendritic $R N A$
The discovery that polyribosomes are selectively localized beneath postsynaptic sites on CNS neurons has led to the hypothesis that some key synaptic proteins are synthesized on site (Steward and Levy, 1982; Steward and Ribak, 1986). The identity of the proteins synthesized by subsynaptic polyribosomes is not yet known; however, there is evidence that at least some of the proteins that are synthesized within dendrites are components of the synaptic junctional specialization (Rao and Steward, 1991).

The latter findings raise the question of whether any integral membrane proteins are synthesized in dendrites. Recent studies have revealed that mRNA for the 1,4,5-inositol triphosphate receptor $\left(\mathrm{IP}_{3} \mathrm{r}\right)$ is present in the dendrites of Purkinje cells $(\mathrm{Fu}-$ ruichi et al., 1993). There also is evidence that mRNAs for members of the glutamate receptor family (Miyashiro et al., 1994) may be present in dendrites of hippocampal neurons in culture. The presence of mRNAs for membrane proteins in dendrites raises the question of whether dendrites also contain the machinery [i.e., rough endoplasmic reticulum (RER) and Golgi apparatus (GA)] that would allow translation of the mRNAs and glycosylation of the protein products. Ultrastructural studies have revealed membranous cisterns in dendrites and spines (Broadwell

\footnotetext{
Received June 5, 1996; revised July 9, 1996; accepted July 11, 1996.

This work was supported by National Institutes of Health Grant NS 12333 to O.S. We gratefully acknowledge Dr. David Castle for his critical review of this manuscript. We thank also Dr. David Meyer for his antibody against Ribophorin I, Drs. Kelly Moremen and Marilyn Farquar for the antibody against $\alpha$-mannosidase II, Dr. Barry D. Shur for the antibody against bovine milk galactosyltransferase, Dr. Jakko Saraste for the antibody against p58, and Dr. Kathryn Howell for the antibody against TGN $38 / 41$.

Correspondence should be addressed to Dr. Enrique R. Torre, Department of Neuroscience, University of Virginia School of Medicine, Box 5148 MR4 Annex, Charlottesville, VA 22908.

Copyright (C) 1996 Society for Neuroscience $0270-6474 / 96 / 165967-12 \$ 05.00 / 0$
}

and Cataldo, 1983; Spacek, 1985; Steward and Reeves, 1988; Martone et al., 1993), but whether these cisterns are components of the RER and the GA is not known. There also is immunocytochemical evidence that RER proteins and GA markers are present in the dendrites of some cell types (De Camilli et al., 1986; Takei et al., 1992; Villa et al., 1992; Lowenstein et al., 1994). However, it is not known whether these organelles participate in the local synthesis and processing of proteins.

The goal of the present study was to define whether the machinery for protein glycosylation is present in the dendrites of hippocampal neurons in culture. These are the same cells in which the distribution of particular mRNA species and the distribution of protein synthetic activity have previously been defined (Kleiman et al., 1990, 1993; Torre and Steward, 1992). The principal approach was to use precursor labeling techniques in conjunction with autoradiography to visualize glycosyltransferase activities that are characteristic of the RER (mannose) or the GA (galactose and fucose). To ensure that labeling reflected local glycosylation rather than transport, we evaluated incorporation in dendrites that had been separated from their cell bodies and in intact neurons that were pulse-labeled in the presence of brefeldin A or at $20^{\circ} \mathrm{C}$ to block the traffic of newly synthesized glycoproteins within the ER or the GA, respectively. To determine whether elements of the RER and Golgi could be detected using standard immunocytochemical techniques, neurons were immunostained for proteins that are considered to be markers for different components of the endomembrane system.

Our results revealed a local incorporation of sugars within proximal and middle dendrites that was blocked by tunicamycin (N-glycosylation inhibitor), and cycloheximide (protein synthesis 
inhibitor). The distribution of labeling was similar to the distribution of immunostaining for elements of the RER and the GA.

Some of these results were communicated in abstract form (Torre and Steward, 1993).

\section{MATERIALS AND METHODS}

\section{Cell culture}

Culture of hippocampal neurons. Cultures of hippocampal neurons were prepared as described by Bartlett and Banker (1984). Briefly, rat fetuses were harvested from anesthetized female rats on day 18 of gestation. The hippocampi from 10 to 15 fetuses were dissected from the brains and treated with $0.25 \%$ trypsin for $15 \mathrm{~min}$ at $37^{\circ} \mathrm{C}$. The tissue was washed in $\mathrm{Mg} / \mathrm{Ca}$-free Hank's balanced salt solution (Life Technologies, Gaithersburg, MD), dissociated by repeated passage through a constricted Pasteur pipette, and filtered through a $70 \mu \mathrm{m}$ Nitex filter. Cells were plated on poly-lysine-treated glass coverslips at a density of $1800 \mathrm{cells} / \mathrm{cm}^{2}$. After 2 $\mathrm{hr}$ at $37^{\circ} \mathrm{C}$, the coverslips were placed cell side down in dishes containing a confluent monolayer of astroglial cells. Cultures were maintained in MEM-N2.1 medium (Bottenstein and Sato, 1979) supplemented with $0.1 \%$ of ovalbumin and $1 \mathrm{~mm}$ pyruvate. Cytosine-arabinoside (Calbiochem, La Jolla, CA) $(5 \mu \mathrm{M})$ was added $3 \mathrm{~d}$ after plating to inhibit glial proliferation.

Preparation of double-surfaced coverslips for the isolation of neurites. The system used to isolate dendrites was prepared as described previously (Torre and Steward, 1992) with slight modifications. Briefly, acid-washed glass coverslips (12 $\mathrm{mm}$ in diameter) were coated with poly-lysine (Sigma, St. Louis, MO) $(1 \mathrm{mg} / \mathrm{ml}$ in $0.1 \mathrm{M}$ borate buffer, $\mathrm{pH} 8.3)$ and covered with a thin layer of collagen I (Collaborative Research, Bedford, MA) (rat tail collagen $2 \mathrm{mg} / \mathrm{ml}$ ) that was polymerized in an atmosphere of ammonia and fixed by heating at $70^{\circ} \mathrm{C}$ for $1 \mathrm{hr}$. A Nucleopore polycarbonate membrane (General Electric, Vallecitos Nuclear Center, Pleasanton, CA) (13 mm diameter, $2 \mu \mathrm{m}$ pore) was applied on top of a second layer of diluted Matrigel (Collaborative Research) that was allowed to polymerize at $37^{\circ} \mathrm{C}$ for $1 \mathrm{hr}$. These sandwiches were sealed on the edges with paraffin.

Hippocampal cell suspensions of 7.5-10 $\times 10^{4}$ cells were plated onto the filter surface of the sandwich. Cells were plated at lower densities than described originally (Torre and Steward, 1992). This condition improves the quality and survival of the cultures. After $2 \mathrm{hr}$ at $37^{\circ} \mathrm{C}$, the sandwiches were placed cell side down in dishes containing a confluent monolayer of astroglial cells. The sandwiches floated on the medium surface throughout the entire culture period. Cultures were maintained in MEM-N2.1 medium, supplemented with $0.1 \%$ of ovalbumin and $1 \mathrm{~mm}$ Na-pyruvate. Cytosine-arabinoside $(5 \mu \mathrm{M})$ was added immediately after plating and again after $2 \mathrm{~d}$ in culture to inhibit glial proliferation. A few days after plating, the cells aggregate and extend neurites, some of which grow through the porous membrane and into the protein matrix where they ramify.

After $10-12 \mathrm{~d}$ in culture, the sandwiches were transferred to a dish containing Hank's BSS, and the polycarbonate membranes were peeled off. The matrix on the glass coverslips contained the neurites that had grown through the porous membrane. These coverslips were subsequently used in the pulse-labeling experiments.

\section{Pulse-labeling experiments}

To maximize sugar incorporation within isolated dendrites or intact neurons, we used the following strategies: (1) Cells and neurites were preincubated and pulse-labeled in a medium in which the glucose concentration was lowered from 7 to $1 \mathrm{gm} / 1$ to ensure a higher uptake of the sugar tracer. Complete elimination of glucose from the medium was not tolerated by either hippocampal cells or dissected neurites, even when the medium was supplemented with pyruvate. (2) Neurites were pulselabeled for $1 \mathrm{hr}$ and with high concentrations of the radioactive sugar precursors to increase the labeling of the endogenous pools of nucleotidesaccharide donors and to promote a more extensive labeling of newly synthesized glycoproteins.

Sugar incorporation in isolated neurites. Isolated neurites were preincubated in conditioned N2.1 medium containing low glucose $(0.1 \%)$ for $1 \mathrm{hr}$ at $37^{\circ} \mathrm{C}$ and then pulsed for $1 \mathrm{hr}$ with $\left[{ }^{3} \mathrm{H}\right]$ mannose $(500 \mu \mathrm{Ci} / \mathrm{ml})$, $\left[{ }^{3} \mathrm{H}\right]$ fucose $(250 \mu \mathrm{Ci} / \mathrm{ml})$, or $\left[{ }^{3} \mathrm{H}\right]$ galactose $(200 \mu \mathrm{Ci} / \mathrm{ml})$ dissolved in the same medium. The coverslips were chased for $20 \mathrm{~min}$ in the presence of $10 \mathrm{~mm}$ of the respective unlabeled sugar and washed in BSS solution. In some experiments in which neurons were pulse-labeled in the presence of tunicamycin (Boehringer Mannheim, Indianapolis, IN) $(5 \mu \mathrm{g} / \mathrm{ml})$, the cells were preincubated for $2 \mathrm{hr}$ with the inhibitor before separating the Nucleopore membrane. The preincubation of the isolated neurites was continued for an additional hour before the pulse with the tritiated sugar was initiated. The protein synthesis dependence of the sugar incorporation was evaluated by pulse labeling the neurites in the presence of the protein synthesis inhibitor cycloheximide (Sigma) $(50 \mu \mathrm{g} / \mathrm{ml})$. To evaluate whether any of the labeling of isolated neurites was attributable to the activity of surface galactosyltransferases (Eckstein and Shur, 1989; Begovac and Shur, 1990), processes were pulse-labeled in the presence of uridyl diphosphatase (UDP)-galactose (Sigma) (1 mM), which is the natural substrate of the enzyme. For these experiments, neurites were preincubated with the drugs for $1 \mathrm{hr}$ before the initiation of the radioactive pulse. In both experiments, the pulse and chase were done in the presence of the inhibitors for the times described for the controls. The neurites labeled with the radioactive sugars were fixed in methanol at $-20^{\circ} \mathrm{C}$ for $7 \mathrm{~min}$ and then treated with methanol/chloroform 1:2 and 2:1 for $15 \mathrm{~min}$ each at room temperature. This serves as a histological fixative and simultaneously extracts glycolipids while glycoproteins are retained (Suzuki, 1963).

Galactose incorporation in intact neurons treated with brefeldin $A$ or incubated at $20^{\circ} \mathrm{C}$. Intact hippocampal neurons were preincubated for $1 \mathrm{hr}$ at $37^{\circ} \mathrm{C}$ in $\mathrm{N} 2.1$ medium containing low glucose $(0.1 \%)$ either with or without (control) brefeldin A $(5 \mu \mathrm{g} / \mathrm{ml})$. Individual coverslips were labeled with $100 \mu \mathrm{l}$ of $\left[{ }^{3} \mathrm{H}\right]$ mannose $(500 \mu \mathrm{Ci} / \mathrm{ml})$ for $1 \mathrm{hr}$ and chased in the same medium containing $10 \mathrm{~mm}$ unlabeled sugar for an additional hour. Other groups of cells were incubated in N2.1 medium containing $20 \mathrm{~mm}$ HEPES, pH 7.4, and $0.1 \%$ glucose at either $37^{\circ} \mathrm{C}$ (control) or $20^{\circ} \mathrm{C}$. Individual coverslips were labeled with $100 \mu \mathrm{l}$ of $\left[{ }^{3} \mathrm{H}\right]$ galactose $(200$ $\mu \mathrm{Ci} / \mathrm{ml}$ ) for $1 \mathrm{hr}$ and chased in the same medium containing $10 \mathrm{~mm}$ unlabeled sugar for an additional hour. The cells were fixed permeabilized as described above.

\section{Immunohistochemistry}

To identify dendritic processes, isolated neurites and cells in culture were immunostained for microtubule-associated protein-2 (MAP2). Cells were fixed in $4 \%$ paraformaldehyde in PBS containing $0.12 \mathrm{M}$ sucrose. After fixation, processes were permeabilized in $0.1 \mathrm{M}$ morpholino-ethanesulfonic (MES) buffer, $\mathrm{pH} 6.8$, containing $2 \mathrm{~mm} \mathrm{MgSO}_{4}, 1 \mathrm{~mm}$ EGTA (MME buffer), and $0.2 \%$ Triton X-100 for $5 \mathrm{~min}$ at room temperature. Coverslips were preincubated in MME containing 10\% BSA and 1\% normal goat serum for $1 \mathrm{hr}$ at $37^{\circ} \mathrm{C}$ to block nonspecific binding. After blocking, coverslips were incubated overnight at $4^{\circ} \mathrm{C}$ with the monoclonal antibody AP14 (1:100), which recognizes MAP2, a specific marker of the dendritic compartment (Cáceres et al., 1984). The coverslips were incubated for $1 \mathrm{hr}$ with biotinylated goat anti-mouse $\mathrm{IgG}$ (Vector Laboratories, Burlingame, CA) (1:250). For the detection of biotinylated secondary antibodies, preparations were incubated for $30 \mathrm{~min}$ at room temperature with Texas Red-labeled extravidin (BRL, Bethesda, MD) (1:500). The cultures were rinsed in PBS and then in water and mounted in elvanol.

Immunohistochemistry for endomembranes. Hippocampal neurons cultured for $14-20 \mathrm{~d}$ were rinsed in $\mathrm{Mg} / \mathrm{Ca}$-free Hank's balanced salt solution and fixed in periodate-lysine phosphate buffer containing $2 \%$ paraformaldehyde (McLean and Nakane, 1974). After fixation, cells were permeabilized in MME buffer containing $0.25 \%$ Triton X-100 for 5 min at room temperature. Coverslips were preincubated in MME buffer containing $10 \%$ BSA and $1 \%$ normal goat serum for $1 \mathrm{hr}$ at $37^{\circ} \mathrm{C}$ to block nonspecific binding. After blocking, coverslips were incubated overnight at $4^{\circ} \mathrm{C}$ with primary antibodies that recognize proteins from (1) the RER [ribophorin I (1:200) (Hortsch and Meyer, 1985)]; and (2) Golgi complex [p58 (1:200) (Saraste and Svensson, 1991), $\alpha$-mannosidase II (1:1000) (Moremen and Touster, 1986), bovine milk galactosyltransferase $(1: 10)$ (Eckstein and Shur, 1989), and TGN38/41 (1:400) (Luzio et al., 1990)].

The markers were detected with biotin-extravidin-FITC as described for MAP2. Most coverslips were double stained with MAP2, in which case, MAP2 was visualized with a rhodamine-conjugated rabbit antimouse antibody (Boehringer Mannheim) (1:200).

\section{Histochemistry}

After immunolabeling, coverslips were stained for 30 min with bisbenzimide (Hoechst 33258, Molecular Probes, Eugene, OR) $(5 \mathrm{ng} / \mathrm{ml})$. At neutral $\mathrm{pH}$, bisbenzimide selectively stains DNA, which is detected as blue fluorescence in UV (Hilwig and Grop, 1975). Thus, bisbenzimide staining reveals any cell bodies that were present on the Matrigel surface. 

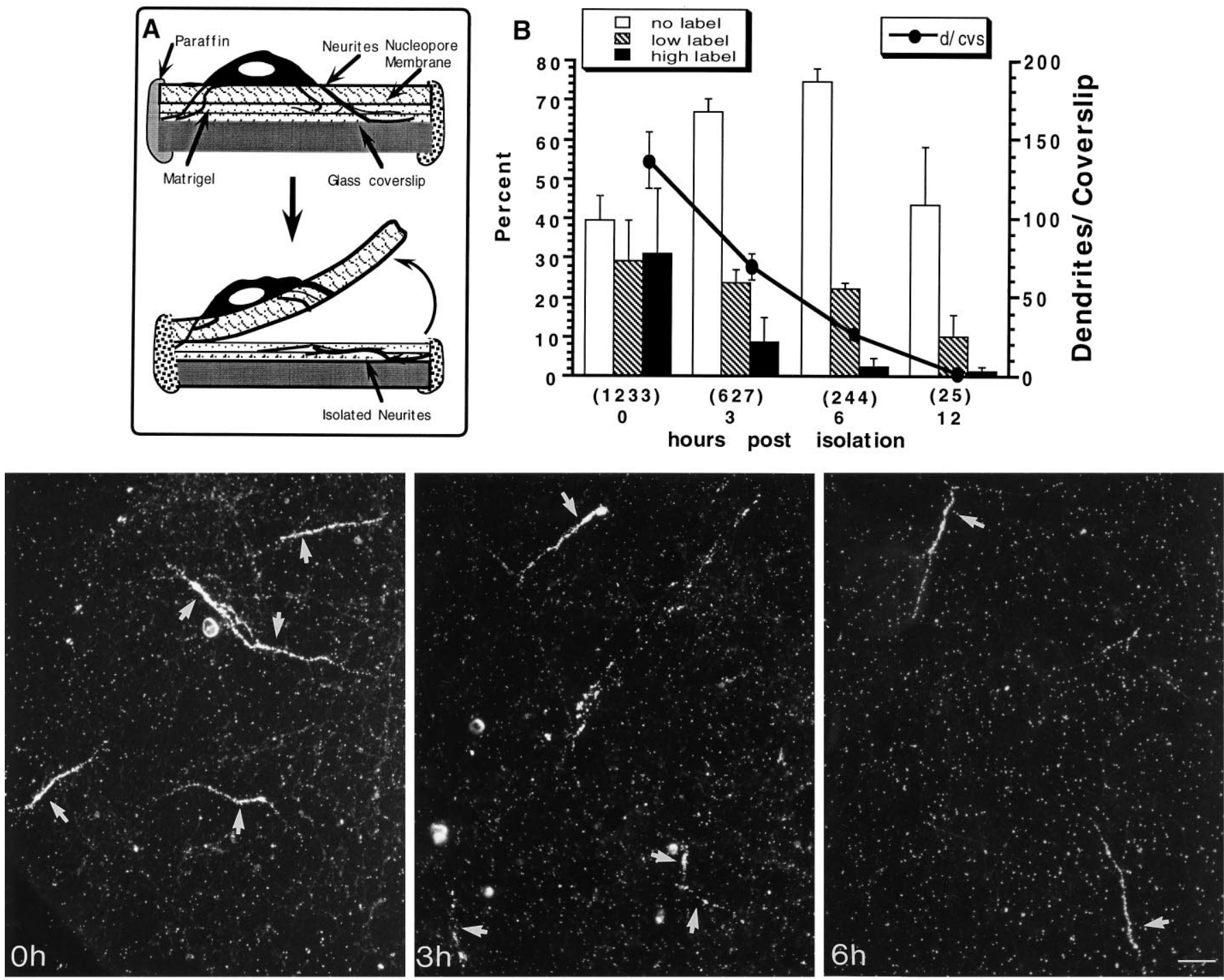

Figure 1. Vitality of isolated dendrites. Hippocampal neurons were cultured for $10 \mathrm{~d}$ on a double-surface coverslip $(A)$ as described in Materials and Methods. The Nucleopore membrane containing the cell bodies was peeled off, leaving a mesh of amputated processes on the second surface. Isolated processes were pulse-labeled with $100 \mu \mathrm{Ci} / \mathrm{ml}\left[{ }^{3} \mathrm{H}\right]$ leucine for $1 \mathrm{hr}$ immediately after the isolation $(0 \mathrm{hr})$ or 3,6 , and $12 \mathrm{hr}$ after the isolation. The processes were fixed-stained for MAP2 and DNA and prepared for autoradiography. The graph in $B$ shows the percentage of labeled dendrites at the different survival times. The percentage of living dendrites slowly decreases with time and drops dramatically by 6 and $12 \mathrm{hr}$ after isolation. Dendrites were considered labeled at low levels when they had scattered patches of 2-3 silver grains along their length. Those processes having strings of densely packed silver grains were counted as highly labeled dendrites. The numbers in parentheses represent the number of MAP2-stained processes counted in nine coverslips from three different experiments. The photographs are representative fields showing the incorporation of $\left[{ }^{3} \mathrm{H}\right] \mathrm{leucine}$ by isolated dendrites at different times after the cut. Scale bar, $25 \mu \mathrm{m}$.

\section{Autoradiography}

After immunostaining, coverslips were dehydrated in graded ethanol, air dried, mounted on glass slides, and dipped in Kodak NTB2 photographic emulsion. After exposure for $10-20 \mathrm{~d}$ at $4^{\circ} \mathrm{C}$, the slides were developed in Kodak D-19 at $15^{\circ} \mathrm{C}$, fixed, and coverslipped using elvanol.

\section{Visualization}

Histological preparations were photographed using epifluorescence and dark-field illumination to localize silver grains over stained processes.

\section{Quantification}

To evaluate the number of dendrites that were able to incorporate sugar precursors, MAP2-stained processes that were labeled were counted and related to the total number of MAP2-stained processes on each coverslip. Dendrites were considered labeled at low levels when they had scattered patches of 2-3 silver grains along their length. Processes having strings of densely packed silver grains were counted as highly labeled dendrites.

\section{RESULTS}

\section{Sugar incorporation in isolated dendrites}

To evaluate whether glycosylation of newly synthesized proteins takes place within dendrites, we studied the incorporation of $\left[{ }^{3} \mathrm{H}\right]$ mannose, $\left[{ }^{3} \mathrm{H}\right]$ galactose, or $\left[{ }^{3} \mathrm{H}\right]$ fucose in dendrites that were physically separated from their cell bodies. This was accomplished using a special two-surfaced culture system described previously (Torre and Steward, 1992) (Fig. 1A).

\section{Survival of isolated dendrites}

The present experiments required that isolated neurites be maintained under different culture conditions and for longer periods of time than originally reported. To evaluate the time range after the cut within which the dissected dendrites still are viable, dendrites 

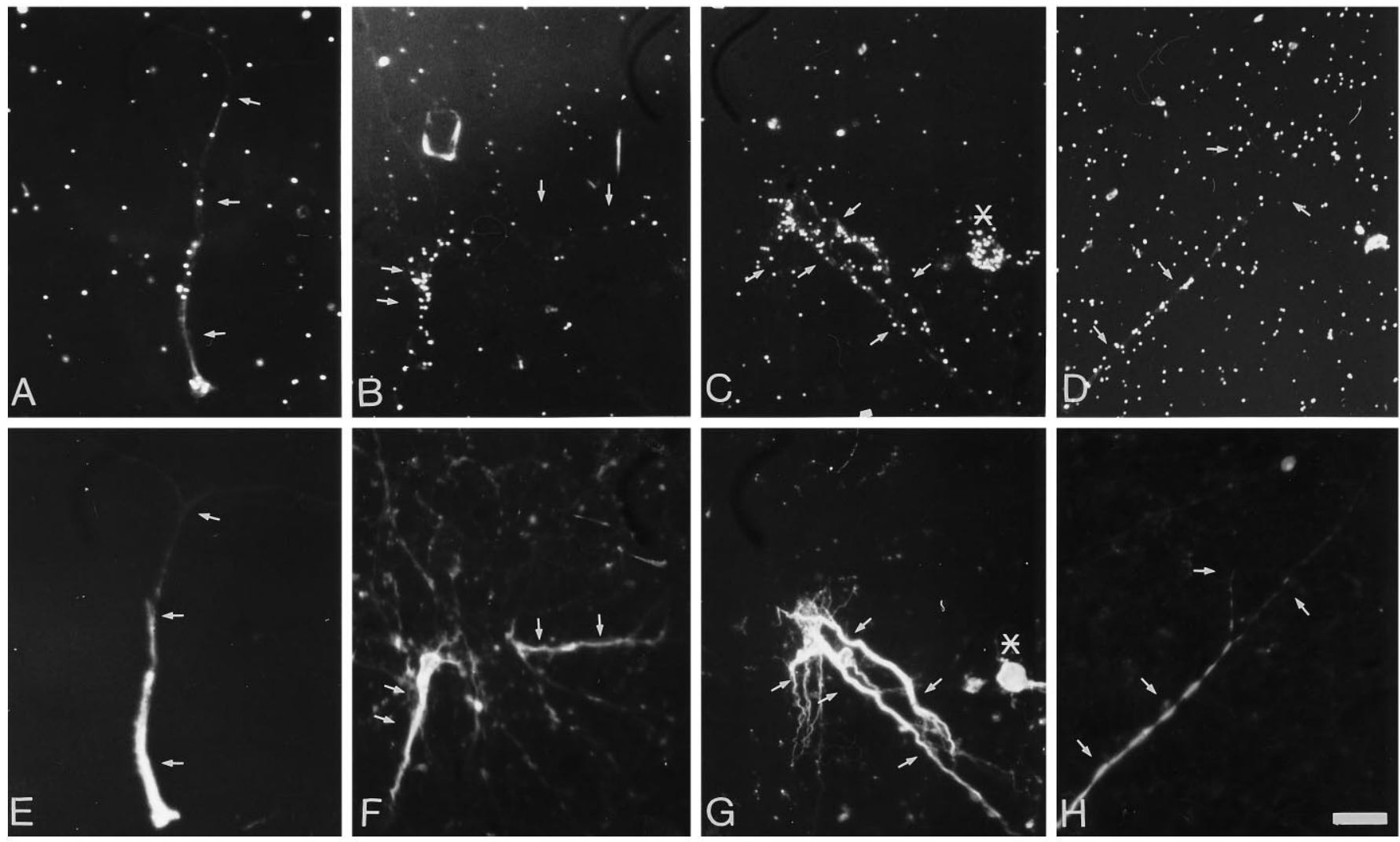

Figure 2. Mannose incorporation in isolated dendrites. Neurites isolated from 10- to 12-d-old cultures were preincubated for $1 \mathrm{hr}$ in low-glucose medium, pulse-labeled with $400 \mu \mathrm{Ci} / \mathrm{ml}\left[{ }^{3} \mathrm{H}\right]$ mannose for $1 \mathrm{hr}$, rinsed in medium containing $10 \mathrm{~mm}$ cold sugar, and fixed and immunostained for MAP2. $A-D$, Sites of $\left[{ }^{3} \mathrm{H}\right]$ mannose incorporation evaluated by autoradiography and dark-field microscopy. $E-G$, MAP2 staining shows colocalization with silver grains. The arrows indicate the location of dendrites. The asterisk indicates the presence of a labeled neuron that was identified by the DNA staining. Scale bar, $25 \mu \mathrm{m}$.

were isolated from 10-d-old cultures and then were pulse-labeled with $\left[{ }^{3} \mathrm{H}\right]$ leucine $(100 \mu \mathrm{Ci} / \mathrm{ml})$ for $1 \mathrm{hr}$ immediately after separation (time 0 ) and at 3,6 , and $12 \mathrm{hr}$ after separation. The coverslips were prepared for autoradiography, and the viability of the cut dendrites was assessed by the presence of silver grains over processes that stained positively for MAP2.

Approximately $60 \%$ of the MAP2-stained neurites incorporated $\left[{ }^{3} \mathrm{H}\right]$ leucine when pulse-labeled immediately after the cut. Many processes became heavily labeled. Approximately $35 \%$ of the MAP2-stained neurites incorporated $\left[{ }^{3} \mathrm{H}\right]$ leucine when pulselabeled $3 \mathrm{hr}$ after the cut and $\sim 25 \%$ when pulse-labeled $6 \mathrm{hr}$ after the cut (Fig. 1B). By $12 \mathrm{hr}$, most neurites had degenerated, although in two experiments, a few neurites still were able to incorporate the labeled precursor. Neurites labeled $3 \mathrm{hr}$ after the cut in medium with low glucose $(1 \mathrm{gm} / \mathrm{l})$ exhibited leucine incorporation that was similar to that seen in normal medium. These results indicate that isolated dendrites remain viable for several hours and continue to be capable of synthesizing protein for at least 3-4 hr after separation.

\section{Incorporation of $\left[{ }^{3} \mathrm{H}\right]$ mannose in isolated dendrites}

Mannose is added to nascent glycoproteins in the RER (Kornfeld and Kornfeld, 1985; Varki and Freeze, 1994). When isolated neurites were pulse-labeled with $\left[{ }^{3} \mathrm{H}\right]$ mannose, $\sim 30 \%$ of the MAP2-positive neurites were radiolabeled. Labeling was not seen over unstained processes (axons). Grain density was highest over proximal (thicker) dendrites and decreased or disappeared in thinner branches (Fig. 2). Because of the characteristic tapering of the dendritic diameter, the thicker and more frequently labeled dendritic region is proximal to the cell body. The level of labeling after exposure to $\left[{ }^{3} \mathrm{H}\right]$ mannose was relatively low compared with that after exposure to $\left[{ }^{3} \mathrm{H}\right]$ leucine.

Tunicamycin inhibits N-glycosylation by interrupting the formation of the mannose-rich oligosaccharide in the RER (Elbein, 1991). When the isolated neurites were pulse-labeled with $\left[{ }^{3} \mathrm{H}\right]-$ mannose in the presence of tunicamycin $(5 \mu \mathrm{g} / \mathrm{ml})$, no labeling was observed (see Figs. 4E, 5). Neurites pulse-labeled with $\left[{ }^{3} \mathrm{H}\right]$ leucine in the presence of tunicamycin still exhibited a pattern of labeling comparable with that of the control neurites (data not shown), suggesting that the effect of tunicamycin was on glycosylation rather than on the synthesis of proteins.

\section{Galactose and fucose incorporation in isolated dendrites}

Galactose and fucose are incorporated into complex oligosaccharides of membrane and secretory glycoproteins in the GA (Kornfeld and Kornfeld, 1985; Varki and Freeze, 1994). Galactose and some derivatives also can be added to proteins in the cytosol as transient or permanent post-translational modifications (Haltiwanger, 1992; Dong, 1993). When isolated neurites were pulselabeled with $\left[{ }^{3} \mathrm{H}\right]$ galactose or fucose, 30 to $40 \%$ of the MAP2stained processes exhibited labeling.

The label over the isolated dendrites was rather patchy but was higher than that seen with mannose. Labeling was highest over the thicker (proximal) end of the isolated dendrite (Fig. $3 A, C$ for galactose, $E, G$ for fucose). Thin processes (presumed distal dendrites) generally were not labeled, although the most heavily 

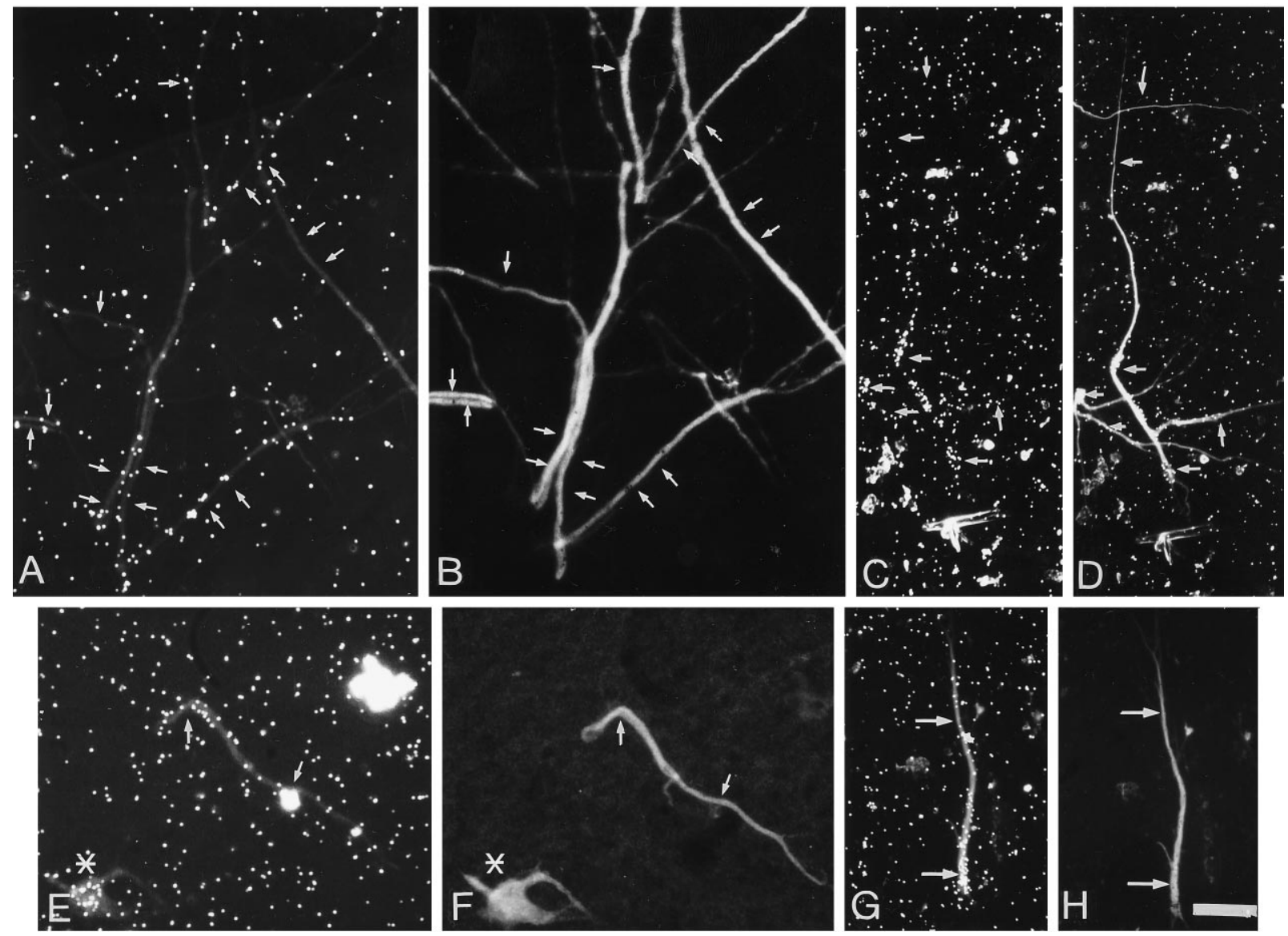

Figure 3. Galactose and fucose incorporation in isolated dendrites. Neurites isolated from 10- to 12-d-old cultures were preincubated for 1 hr in low-glucose medium, pulse-labeled with $200 \mu \mathrm{Ci} / \mathrm{ml}\left[{ }^{3} \mathrm{H}\right]$ fucose or $100 \mu \mathrm{Ci} / \mathrm{ml}\left[{ }^{3} \mathrm{H}\right]$ galactose for $1 \mathrm{hr}$, rinsed in medium containing $10 \mathrm{~mm}$ cold sugar, and fixed and immunostained for MAP2. $A, C$, Autoradiographic localization of the sites of $\left[{ }^{3} \mathrm{H}\right]$ galactose incorporation. $E, G$, Autoradiographic localization of $\left[{ }^{3} \mathrm{H}\right]$ fucose incorporation. $B, D, F, H$, The parts show that the sugar incorporation is localized over MAP2-stained processes. The arrows indicate the localization of dendrites identified by MAP2 staining. The asterisk indicates the presence of a labeled neuron that was identified by the DNA staining. Scale bar, $25 \mu \mathrm{m}$.

labeled processes were labeled throughout their extent. As was the case with mannose incorporation, axons remained unlabeled.

The fact that galactosyltransferases may be found on the cell surface (Shur, 1989), particularly when the cells are growing over laminin-containing substrates (Eckstein and Shur, 1989; Begovac and Shur, 1990), led us to evaluate whether the labeling was attributable to surface addition of sugars to membrane proteins. If galactose is incorporated in the cell surface, UDP-galactose, an impermeant precursor, should compete with the labeled precursor leading to a reduction of the labeling. However, when cells were pulse-labeled in the presence of UDP-galactose, the label of neurites essentially was unaffected (Figs. 4J, 5).

In contrast, the dendritic incorporation of galactose and fucose was drastically reduced by tunicamycin (Figs. 4E,I, 5). Only a few dendrites showed some scattered silver grains. These observations underline the intracellular locus of the sugar incorporation.

\section{Incorporation of sugars in dendrites is dependent on protein synthesis}

The labeling of membrane and secretory proteins depends on the continued availability of newly synthesized precursors (Kornfeld and Kornfeld, 1985; Varki and Freeze, 1994). In contrast, the glycosylation of cytosolic proteins appears to be a process independent of the synthesis of new proteins (Haltiwanger, 1992;
Dong et al., 1993). Thus, sugar incorporation mediated by glycosyltransferases of the RER and GA should be disrupted by inhibiting protein synthesis. When isolated neurites were pulse-labeled with either $\left[{ }^{3} \mathrm{H}\right]$ mannose or galactose after blocking the synthesis of proteins with cycloheximide $(50 \mu \mathrm{g} / \mathrm{ml})$, most of the MAP2stained processes did not exhibit labeling (Figs. 4C,H, 5).

Taken together, the results suggest that there is a compartment within dendrites that is able to glycosylate recently synthesized proteins in a way similar to that for the RER-GA complex.

\section{Pulse labeling of intact neurons at low temperature and in the presence of brefeldin A}

To corroborate the results obtained with isolated dendrites, we wished to evaluate the distribution of glycosyltransferase activities in intact neurons using autoradiography to visualize sites of sugar incorporation. However, this approach is complicated by the fact that neurons are capable of very rapid transport of glycoproteins after their synthesis (Hammerschlag et al., 1982). Such transport could move recently synthesized proteins from the cell body to the tip of the longest dendrites within minutes (assuming a transport rate of $400 \mathrm{~mm}$ per day). To circumvent this problem, we pulselabeled intact neurons under conditions in which the movement of recently synthesized glycoproteins within the RER and GA is blocked. 

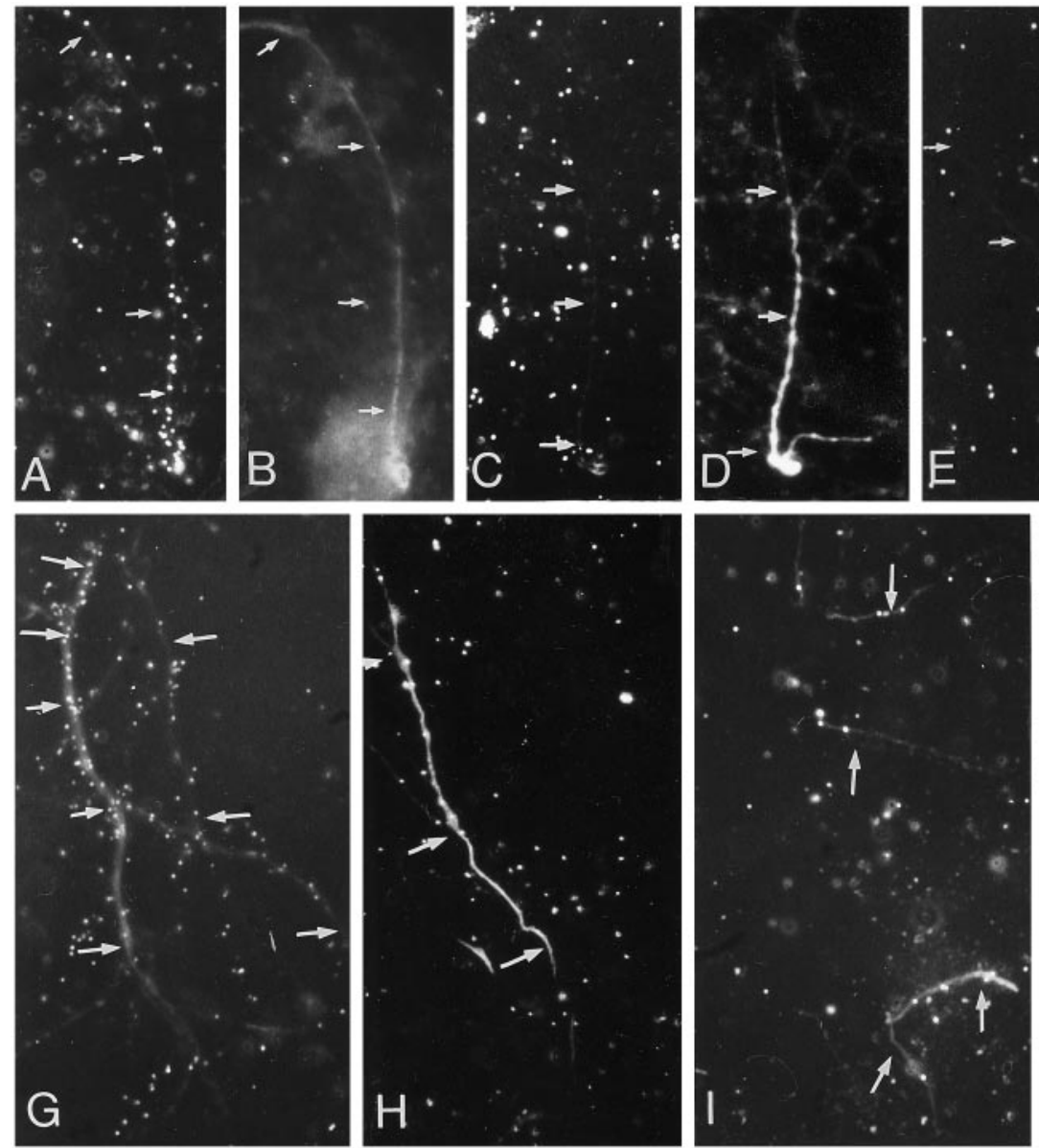
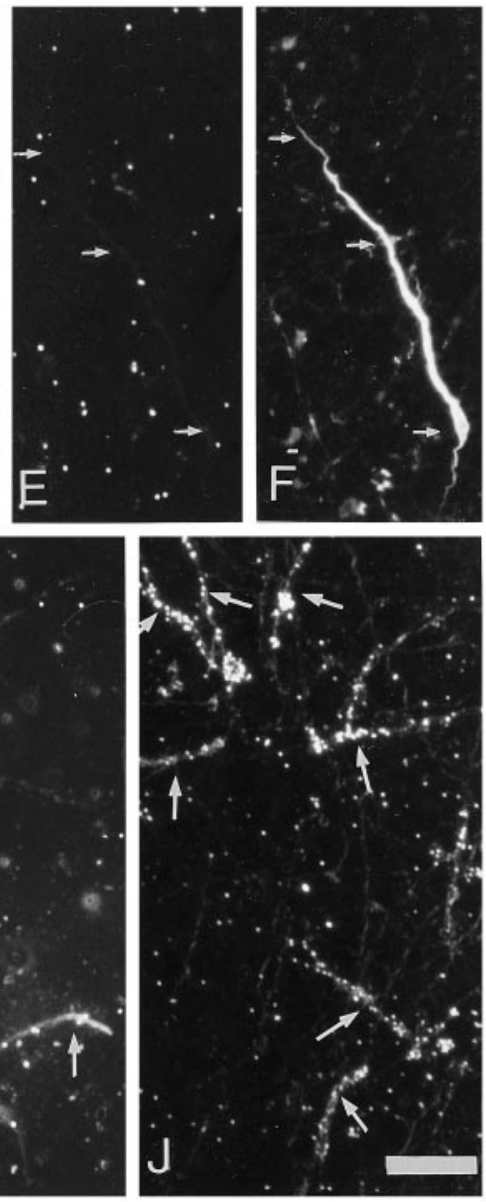

Figure 4. Labeling of isolated dendrites was depressed by inhibiting the synthesis and N-glycosylation of proteins but not by competing with surface glycosyltransferases. Isolated dendrites were preincubated for $1 \mathrm{hr}$ in low-glucose medium containing $50 \mu \mathrm{g} / \mathrm{ml}$ cycloheximide $(C, H), 5 \mu \mathrm{g} / \mathrm{ml}$ tunicamycin $(E, I)$, or $5 \mathrm{~mm}$ UDP-galactose $(J)$; control cells $(A, G)$ were incubated with no drugs. Cells were pulse-labeled with $\left[{ }^{3} \mathrm{H}\right] \mathrm{mannose}($ upper panel $)$ or $\left[{ }^{3} \mathrm{H}\right]$ galactose (lower panel) for $1 \mathrm{hr}$, washed in medium containing $10 \mathrm{~mm}$ cold sugar, and fixed and immunostained for MAP2 (B, $D, F$; in $G-J$, immunofluorescence for MAP2 was combined with dark-field illumination). The arrows indicate the location of dendrites. Scale bar, $25 \mu \mathrm{m}$.

Incubation of cells in the presence of brefeldin A induces the rapid fusion of the GA with the ER (Lippincott Schwartz et al., 1989) (see Fig. 8) without affecting the synthesis of proteins. Incubation at $20^{\circ} \mathrm{C}$ inhibits the traffic of newly synthesized proteins between the GA and the plasma membrane without severely altering the organization of the endomembrane system (Kuismanen and Saraste, 1989). As a result, newly synthesized proteins are glycosylated but cannot exit the ER (brefeldin A) or the TGN $\left(20^{\circ} \mathrm{C}\right)$, and so they accumulate within these organelles. In untreated cells, glycoproteins are rapidly transported into axons once they exit the GA, and this transport is evidenced by rapid labeling of axons of neurons in culture (see below). Thus, the effectiveness of the treatments can be verified by the reduction in the axonal labeling.

\section{Distribution of newly synthesized glycoproteins in brefeldin} A-treated neurons

Autoradiographs of control cells that have been incubated for $1 \mathrm{hr}$ in $\left[{ }^{3} \mathrm{H}\right]$ mannose or galactose revealed silver grains densely packed over the cell body and extending into all processes, including axons (Fig. $6 A$ for mannose, $C$ for galactose). This is consistent with a rapid transport of recently synthesized glycoproteins. $\left[{ }^{3} \mathrm{H}\right]$ mannose labeling of axons was reduced by $\sim 96 \%$ with brefel$\operatorname{din} \mathrm{A}(0.59 \pm 0.02 \mathrm{grains} / \mu \mathrm{m}$ in control cells to $0.021 \pm 0.003$ grains/ $\mu \mathrm{m}$ after brefeldin A; $n=40$ ), demonstrating the expected blockade of rapid axonal transport. In contrast, dendrites still were heavily labeled when cells were pulse-labeled with mannose in the presence of brefeldin A (Fig. 6B), consistent with local mannose incorporation within dendrites. Dendritic labeling decreased in a proximo-distal manner and generally was absent in distal dendritic branches. Silver grains were not evenly distributed in all dendrites. Thus, in a given cell, some dendrites were densely labeled, whereas others were lightly labeled or unlabeled (Fig. 6B).

\section{Distribution of newly synthesized glycoproteins in neurons maintained at $20^{\circ} \mathrm{C}$}

The sites of accumulation of recently synthesized glycoproteins in cells incubated at $20^{\circ} \mathrm{C}$ provide an estimate of the distribution of the GA in intact hippocampal neurons. Cells that were pulselabeled with galactose at $20^{\circ} \mathrm{C}$ exhibited labeling that was more tightly concentrated over the region of the cell body than was the case in cells incubated at $37^{\circ} \mathrm{C}$ [compare Fig. $6 \mathrm{C}$ (galactose at $37^{\circ} \mathrm{C}$ ) with $D$ (galactose at $20^{\circ} \mathrm{C}$ )]. Axons exhibited little, if any, labeling $\left(0.09 \pm 0.005\right.$ grains $/ \mu \mathrm{m}$ at $20^{\circ} \mathrm{C}, n=40$ vs $0.75 \pm 0.002$ grains $/ \mu \mathrm{m}$ at $\left.37^{\circ} \mathrm{C}\right)$, consistent with the expected blockade of rapid transport.

Although axonal labeling was greatly reduced or eliminated, labeling was clearly present over dendrites (Fig. $6 D, E$ ). However, 


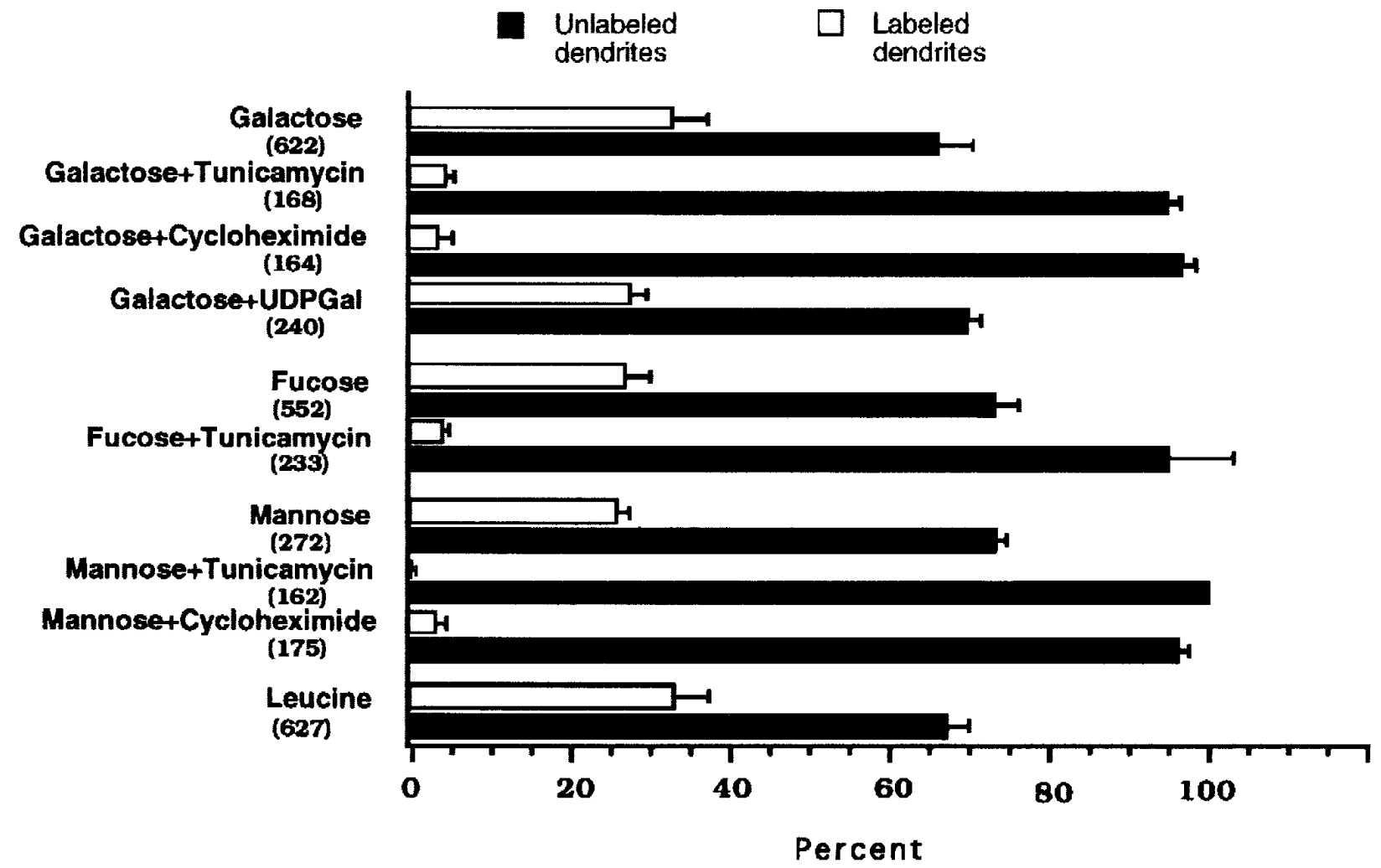

Figure 5. Effect of the inhibition of N-glycosylation, protein synthesis, and surface glycosyltransferases on the labeling of isolated dendrites with the tritiated sugar precursors mannose, galactose, and fucose. Neurites isolated as described in Materials and Methods were treated with tunicamycin (5 $\mu \mathrm{g} / \mathrm{ml})$, cycloheximide $(50 \mu \mathrm{g} / \mathrm{ml})$, or the impermeant sugar precursors UDP-galactose (5 mM) and pulse-labeled for $1 \mathrm{hr}$ with tritiated sugars. The bars represent the proportion of labeled and unlabeled MAP2-stained processes \pm SEM after the different treatments. The numbers in parentheses indicate the number of dendrites evaluated in at least two different experiments. Controls were compared with the incorporation of $\left[{ }^{3} \mathrm{H}\right]$ leucine by isolated dendrites in similar conditions.

in contrast to the cells that were pulse-labeled at $37^{\circ} \mathrm{C}$, the labeling was concentrated over proximal dendrites, decreasing to near background levels over middle and distal dendrites (Fig. 6D). Many cells were labeled only in the cell body and very proximal dendrites. Dendritic labeling after galactose exposure was detected in $43.78 \pm 8.03 \%$ of the cells.

\section{Immunolocalization of markers of the endomembrane system}

The localization of the glycosyltransferase activities was compared with the distribution of organelles of the RER and GA, visualized by immunofluorescence microscopy of cultured hippocampal cells using antibodies against proteins localized in different compartments of the RER and GA.

\section{Endoplasmic reticulum}

The distribution of the RER in cultured hippocampal cells was assessed by using antibodies that recognize ribophorin I. Immunolabeling for ribophorin I was very intense in the perinuclear region of the cell body and extended from 50 to $120 \mu \mathrm{m}$ into the dendritic shaft of most neurons. Distal dendrites and axons appeared unstained (Fig. 7A). These results were consistent with the autoradiographic distribution of mannose labeling in isolated dendrites and intact neurons and provided the background against which the subcellular distribution of the GA can be compared (Fig. $7 B$ ).

\section{Golgi apparatus}

The organization of the Golgi complex in hippocampal neurons in culture was assessed by immunodetection of proteins specifically localized in the different compartments of the GA. Immunostaining for these markers (Fig. $8 A-D$ ) was localized in the cell body in all neurons and in the dendrites of $\sim 30 \%$ of the cells (Fig. $8 E$ ). In contrast, axons were always devoid of label (Figs. 7, 8). The immunostaining pattern for each Golgi marker is illustrated in Figure $8 A-D$. The distribution of the cis-most region of the Golgi complex was evaluated using an antibody that recognizes a protein of $58 \mathrm{~K}$ (p58) that has been shown to be enriched in the intermediate or salvage compartment and the cis-cisterns of the GA (Saraste and Svensson, 1991; Bonatti and Torrisi, 1993). The antibody-stained small structures within the cell body and in proximal regions of dendrites (Fig. $8 A$ ). In some instances, these stained structures were detected in distal dendrites (data not shown).

The antibody against $\alpha$-mannosidase II that stains the intermediate cisterns of the GA (Moremen et al., 1991) delineated small and large elongated elements that were abundant in the cell body and frequently extended into proximal dendrites (Fig. 8B). Similarly, $\beta$-galactosyltransferase, an enzyme that is localized in the trans-Golgi cisterns (Eckstein and Shur, 1989; Lopez et al., 1989), was detected in elongate structures that frequently extended into proximal dendrites (Fig. $8 \mathrm{C}$ ). In contrast, the antibody against TGN 38/41, a complex N-glycoprotein resident of the trans-Golgi network (Luzio et al., 1990), stained small, rounded structures in 

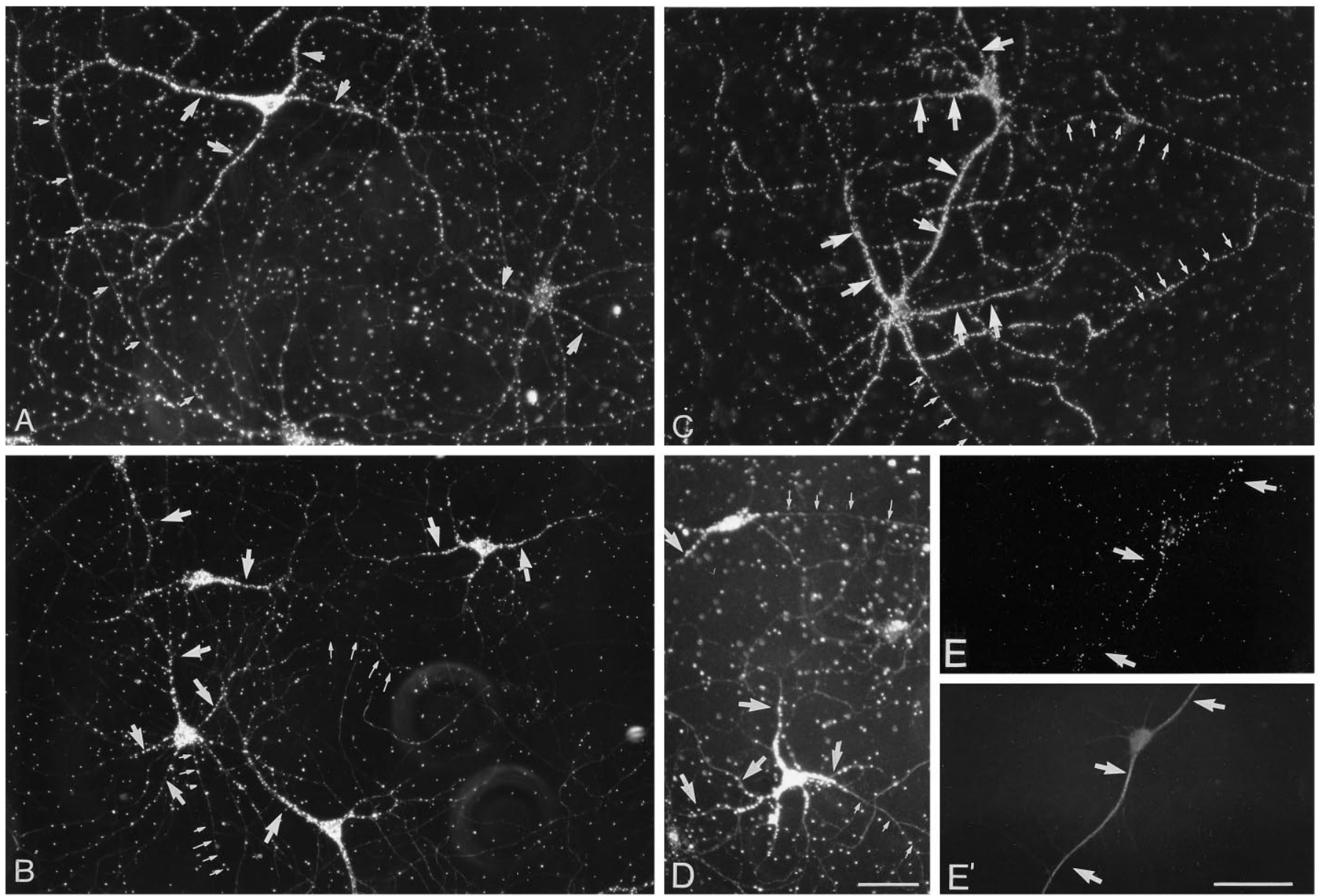

Figure 6. Effects of brefeldin A and temperature on the localization of newly synthesized glycoproteins in hippocampal neurons. Fifteen-day-old neurons were pulse-labeled for $1 \mathrm{hr}$ with $\left[{ }^{3} \mathrm{H}\right]$ mannose at $37^{\circ} \mathrm{C}$ with or without (control) brefeldin $\mathrm{A}(5 \mu \mathrm{g} / \mathrm{ml}$ ) to block the exit of newly synthesized glycoproteins from the ER. Another group of cells was pulse-labeled with $\left[{ }^{3} \mathrm{H}\right]$ galactose at $37^{\circ} \mathrm{C}$ (control) or $20^{\circ} \mathrm{C}$ to block the exit of proteins from the trans-Golgi compartment. The distribution of newly synthesized glycoproteins was evaluated by autoradiography. $A$, Control cells pulse-labeled with $\left[{ }^{3} \mathrm{H}\right] \mathrm{mannose}$. $B$, Cells labeled with $\left[{ }^{3} \mathrm{H}\right]$ mannose in the presence of brefeldin A. $C$, Control cells pulse-labeled with $\left[{ }^{3} \mathrm{H}\right]$ galactose at $37^{\circ} \mathrm{C}$. $D, E$, Cells labeled with $\left[{ }^{3} \mathrm{H}\right]$ galactose at $20^{\circ} \mathrm{C}$. In control cells, newly synthesized glycoproteins were localized in the cell body, dendrites (large arrows), and axons (small arrows). In cells treated with brefeldin $\mathrm{A}$ or at $20^{\circ} \mathrm{C}$, silver grains concentrate in the cell body and proximal or medial dendrites that were identified by their morphology $(B, D)$ or MAP2 staining $\left(E^{\prime}\right)$. The label was significantly reduced in axons. Scale bar, $50 \mu \mathrm{m}$.

the cell body and dendrites (Fig. 8D). Although staining occasionally was present in third-order dendritic branches, staining usually was not seen beyond the first branch point. The different GA structures clearly distributed into the shaft of the dendrite but were undetectable within dendritic spines. Double staining with synaptophysin suggested that there is no correlation between the presence of synaptic contacts and the localization of the GA in dendrites (data not shown) (Torre and Steward, 1995).

To evaluate the distribution of staining in different cellular compartments, cells present in each coverslip were counted and classified as follows: (1) cells showing positive staining for Golgi markers only in the cell body, (2) cells showing positive staining for Golgi markers in only one dendrite, or (3) cells showing staining for Golgi organelles that extended for at least one cell diameter into several dendrites. Figure $8 E$ shows that Golgi elements stained by different antibodies were restricted to the cell body of $\sim 70 \%$ of the neurons. Approximately $20 \%$ of the cells also showed stained structures in one dendrite between 30 and $100 \mu \mathrm{m}$ from the cell body. In $10 \%$ of the cells, staining was observed in all the dendrites. A similar distribution of staining was found with all the GA antibodies.
Treatment with brefeldin A led to a rapid alteration in the immunostaining pattern for elements of the GA. After a $10 \mathrm{~min}$ treatment, most cells exhibited a diffuse staining pattern for $\alpha$-mannosidase rather than the punctate staining characteristic of untreated cells (Fig. 8G). This diffuse staining sometimes extended into proximal dendrites and axons. After $60 \mathrm{~min}$, staining was concentrated around the nucleus and very proximal dendrites (Fig. $8 H$ ). The staining for $\alpha$-mannosidase II seemed to relocate into a distinct compartment that, as judged by double staining with PDI, resembles the ER (data not shown). These observations are consistent with the known alterations that brefeldin $\mathrm{A}$ induces in the GA in non-neuronal cells (Lippincott Schwartz et al., 1989). The effects of brefeldin A on the distribution of $\alpha$-mannosidase II provide additional support for the identification of stained structures as part of the Golgi complex.

\section{DISCUSSION}

Our results provide evidence that elements that function like the RER and GA extend into dendrites of hippocampal neurons in culture. This conclusion is based on the following: (1) a tunicamycin-sensitive and protein synthesis-dependent incorpora- 

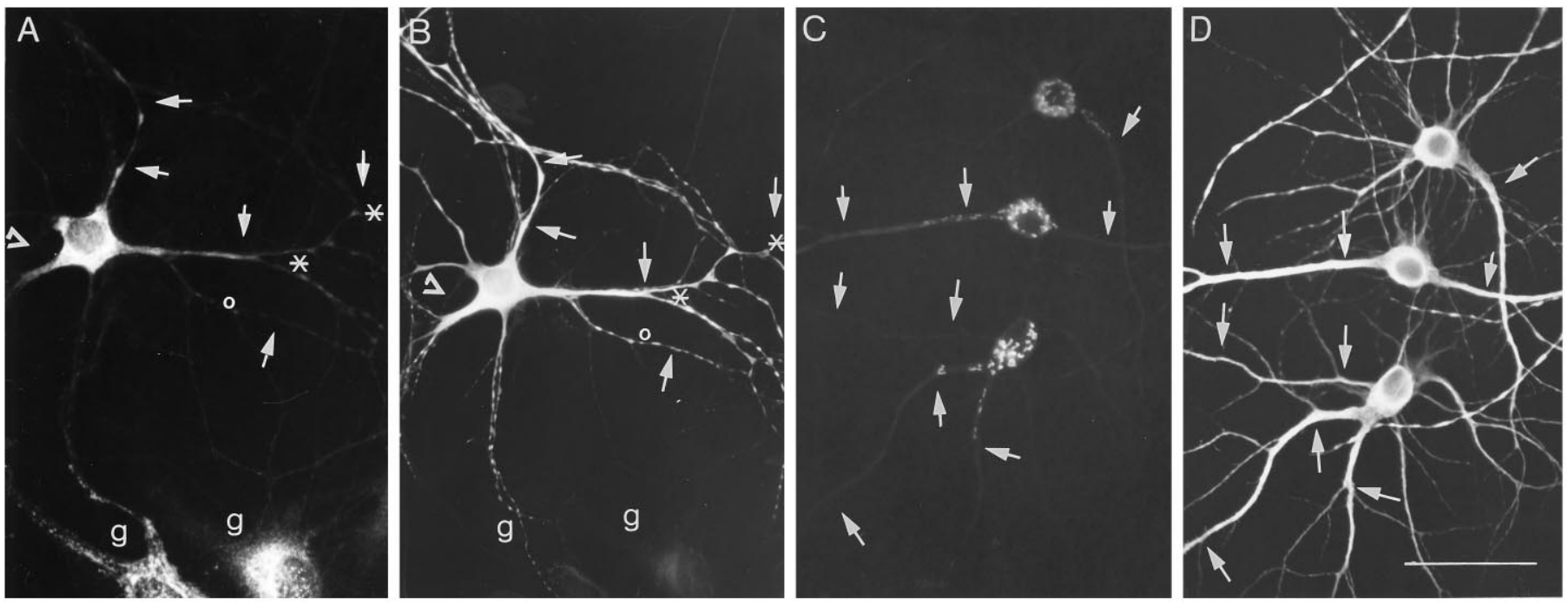

Figure 7. Immunofluorescent localization of the endomembrane system in hippocampal neurons in culture. Fourteen-day-old neurons were fixed and stained for markers of the ER and GA. $A$, Localization of the rough ER protein ribophorin I. Note the accumulation of stained ER structures at branch points (asterisks) as well as the absence of label in some dendritic branches (open circles). Axons (open triangles) remained unlabeled. $g$ indicates glial cell. $C$, Distribution of the medial cisterns of the GA as revealed by $\alpha$-mannosidase II staining. As is evident, immunostained elements extended into dendrites; indeed, they have a similar subcellular distribution as the immunostaining for the RER. Dendrites (arrows) were identified by double staining for MAP2 $(B, D)$. Scale bars, $50 \mu \mathrm{m}$.

tion of tritiated sugar precursors by amputated dendrites; (2) the somatodendritic localization of newly synthesized glycoproteins in neurons treated with brefeldin $\mathrm{A}$ or at $20^{\circ} \mathrm{C}$; and (3) the immunolocalization of the RER and GA markers in proximal and middle dendrites.

\section{RER-associated glycosyltransferase activity}

Translation of secretory and membrane proteins and the initial step in glycosylation (i.e., mannosylation) take place in the RER (Kornfeld and Kornfeld, 1985; Hammond et al., 1994). Our results revealed local incorporation of $\left[{ }^{3} \mathrm{H}\right]$ mannose within dendrites that was sensitive to tunicamycin and protein synthesis inhibitors. Thus, this finding suggests the presence of functional RER within dendrites that is capable of mediating the first step in protein glycosylation.

The autoradiographic and immunochemical observations in intact hippocampal neurons in culture yielded consistent evidence regarding the distribution of RER in dendrites. Specifically, labeling after exposure to $\left[{ }^{3} \mathrm{H}\right]$ mannose in brefeldin A-treated neurons was distributed over the cell body and proximal dendrites in a pattern that resembled that of ribophorin I. This distribution is consistent with electron microscopic observations showing membrane-bound ribosomes along dendrites of the dentate gyrus and pyramidal neurons of the hippocampus (Steward and Levy, 1982; Steward and Reeves, 1988). The distribution of immunolabeling for the RER was more extensive than that reported by Krijnse-Locker et al. (1995) using similar cultures. Because these authors also detect RER staining within proximal dendrites of a few cells, the discrepancy with our results may reflect differences either in the state or developmental age of the cultures or the immunocytochemical techniques.

\section{Golgi-associated glycosyltransferase activities}

Our interpretation that the GA is present in dendrites is based on the finding that in amputated dendrites, the labeling after exposure to sugar precursors was inhibited by tunicamycin and cycloheximide but not by cold UDP-galactose in the incubation me- dium. Thus, the results suggest that within dendrites, sugars are linked to newly synthesized N-glycoproteins in a Golgi-like compartment rather than in the cytosol or on the dendrite surface.

In general, autoradiographic studies of the distribution of glycosyltransferase activities as well as immunocytochemical studies of the distribution of markers of the distinct compartments of the GA in intact neurons provided consistent data. Both approaches revealed the presence of GA markers or glycosyltransferase activity characteristic of the GA in $\sim 30-40 \%$ of the dendrites in intact neurons. The only inconsistency was that the spatial distribution of glycosyltransferase activity revealed by pulse chase experiments in intact neurons was somewhat more extensive than the distribution of the GA markers as revealed by immunocytochemistry. There are several possible explanations for this difference. First, it is possible that the immunocytochemical approach is not sufficiently sensitive to detect small elements of the GA that, nevertheless, possess sufficient glycosyltransferase activity to be detectable using autoradiographic techniques. Second, we cannot rule out the possibility that some of the distal labeling in cells treated with brefeldin A or low temperature is the result of somatodendritic transport of cytosolic glycoproteins (Dong et al., 1993) or glycoproteins that are not processed through the GA (Morré et al., 1979).

The autoradiographic studies of sites of glycosyltransferase activity in amputated dendrites confirm the presence of this activity in at least the proximal portions of the dendrites. However, there are some inconsistencies in the proportion of dendrites exhibiting glycosyltransferase activity. Given that only $\sim 30 \%$ of the neurons exhibit immunostaining for the GA, it is surprising that $30-40 \%$ of the isolated dendrites exhibited labeling after pulse labeling with galactose or fucose. The reason is that only $\sim 35 \%$ of the total number of MAP2-stained dendrites remain viable (as evidenced by an ability to incorporate leucine). If dendrite survival was random, one would expect $30 \%$ of this surviving population to contain elements of the GA detectable by immunostaining. Thus, one would expect only $\sim 10 \%$ of the iso- 

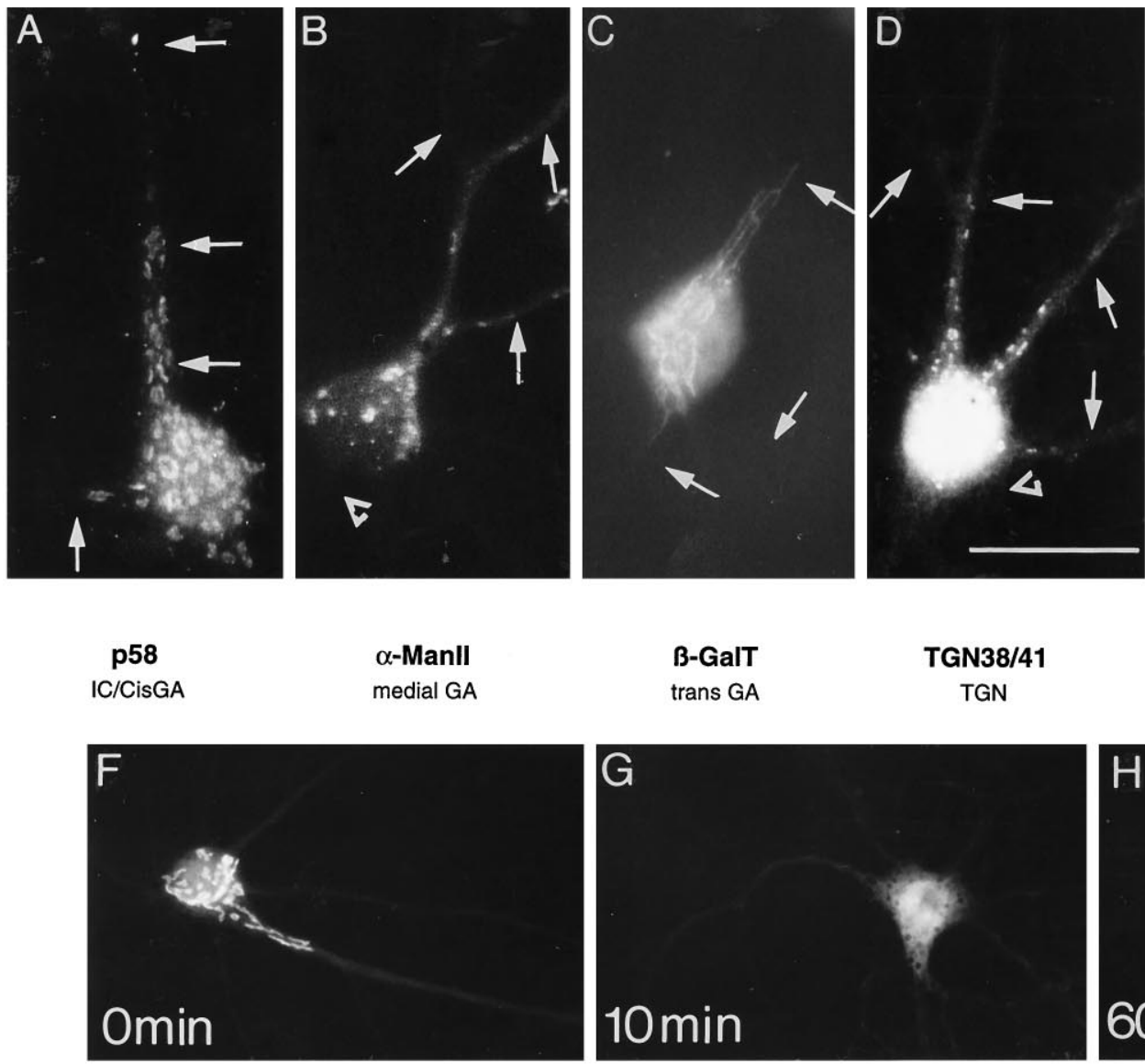

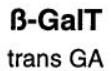

B-GalT

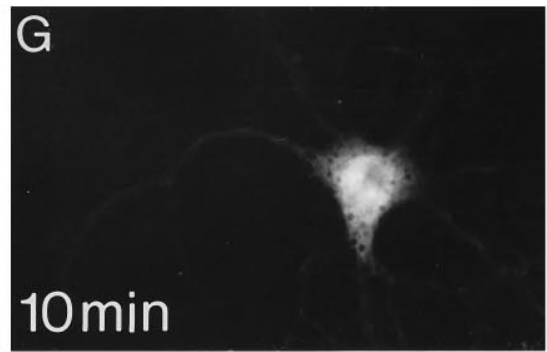

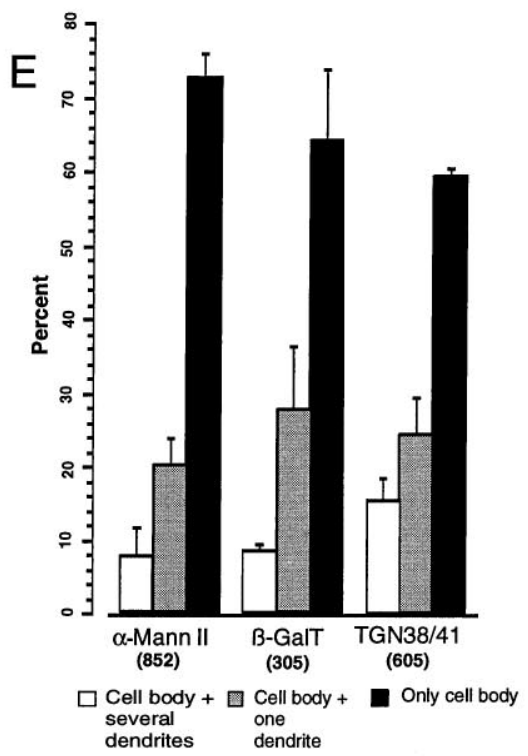

Figure 8. Dendritic localization of different Golgi compartments in hippocampal neurons in culture. Fourteen-day-old cultures were stained for p58 $(A)$, $\alpha$-ManII $(B), \beta$-galactosyltransferase $(\beta$ GalT) $(C)$, or TGN 38/41 $(D)$. Stained puncta were observed concentrated within the cell body and frequently extending into dendrites that were identified by double staining for MAP2 (arrows). The staining was not found in axons (open triangles). E, Distribution of different Golgi compartments in 14- to 20-d-old hippocampal neurons in culture. Stained cells were counted and classified according to whether the immunostained structures were localized only in the cell body, in the cell body and one dendrite, or in the cell body and several dendrites. The bars represent the percentage \pm SEM of cells having a given staining distribution. The numbers in parentheses represent the number of cells counted for each antibody tested. The lower section shows the effect of brefeldin A on the localization of Golgi organelles. Fifteen-day-old neurons were stained for $\alpha$-mannosidase II after treatment with $5 \mu \mathrm{g} / \mathrm{ml}$ brefeldin A. $F$, Control; $G, 10 \mathrm{~min}$ in brefeldin A; $H, 60 \mathrm{~min}$ in brefeldin A. Note the rapid redistribution of this marker induced by brefeldin A. Scale bars, $25 \mu \mathrm{m}$.

lated dendrites to exhibit glycosylation activity. The three possible explanations for this discrepancy are: (1) There may be glycosylation activity in the absence of a GA that is detectable by immunostaining; (2) A greater number of dendrites may possess GA in the sandwich culture conditions; and (3) Dendrites that have a well-developed endomembrane system may be better able to survive the isolation.

In a recent study, Krijnse-Locker et al. (1995) concluded that the GA was essentially absent from dendrites based on immunocytochemical studies of the distribution of $\mathrm{p} 58, \alpha$-mannosidase II, and TGN38/41. The differences between our results and theirs cannot be attributable to a difference in antibodies, because the same antibodies were used. Thus, the differences in results may be attributable to the immunocytochemical techniques or the state of the cultured neurons. It is important to note that Krijnse-Locker et al. did find that other markers of the intermediate compartment (i.e., KDEL receptor, $\beta$-COP, rab1, and rab2) were present in the proximal dendrites of some neurons. Interestingly, Lowenstein et al. (1994) showed that TGN 38 extended into proximal dendrites of cultured cortical neurons.

\section{Possible role of the dendritic endomembrane system in protein synthesis}

The present results reveal the presence of glycosylation activity (implying functional RER and GA) in proximal and even middle dendritic regions, from which all but a few mRNAs are excluded (for review, see Steward, 1995). Thus, the dendritic RER and GA may be important for the synthesis and processing of a particular subset of glycoproteins. If this is so, then the distribution of the RER and GA within dendrites may indicate the sites of synthesis and processing of these proteins.

At this point, it is not known whether mRNAs for glycoproteins are present in the dendrites of hippocampal neurons in culture. Thus, it is not possible to compare the distribution of RER and GA markers with the distribution of particular mRNAs. The only mRNA for a glycoprotein that has been shown to be present in dendrites at relatively high levels is the mRNA for the $\mathrm{IP}_{3} \mathrm{r}$, and this conclusion is based exclusively on studies of mRNA distribution in brain sections (Furuichi et al., 1993). These studies indicated that the $\mathrm{IP}_{3} \mathrm{r}$ mRNA is present in the dendrites of Purkinje cells of the cerebellum (Furuichi et al., 1993). Interestingly, other 
studies have revealed that $\mathrm{BiP}$, a protein that is enriched in the RER (Gething and Sambrook, 1992), also appears throughout the molecular layer of the cerebellum (Villa et al., 1992). The IP $_{3} \mathrm{r}$ mRNA is present at much lower levels in the hippocampus, where it is concentrated in the cell body layer but also is present at lower levels in proximal dendritic laminae in the same general localization pattern that has been described for Golgi markers in vivo (De Camilli et al., 1986; Gonatas et al., 1989). Thus, differences in the subcellular distribution of RER markers in hippocampal neurons versus Purkinje cells are paralleled by differences in the distribution of at least one mRNA for an integral membrane protein.

Whether mRNAs for other glycoproteins are present in dendrites remains to be established. In this regard, there is evidence that mRNAs for subunits of neurotransmitter receptors are present in dendrites at some level (Miyashiro et al., 1994). This evidence derives from experiments in which RNA harvested from isolated dendrites of neurons in culture was PCR amplified and particular mRNAs assayed by reverse Northern blotting techniques. However, so far, the dendritic localization of mRNAs for neurotransmitter receptors has not been confirmed by in situ hybridization. Thus, at this time, there are no data that would indicate the presence of mRNAs for glycoproteins in distal dendrites of hippocampal neurons beyond the domains in which elements of the RER and GA can be found.

The present observations raise a number of new questions about the nature and significance of dendritic protein synthetic machinery. The distribution of endomembrane organelles in dendrites suggests that membrane and secretory proteins can be produced in broad regions of the dendrite. However, these proteins could be fully glycosylated only in proximal segments. This raises the interesting possibility that glycoproteins synthesized in distal dendrites are mostly of the high mannose type that could be produced in the RER. Further characterization of the protein synthetic machinery will likely help to reveal the role of local protein synthesis and processing in dendritic function.

\section{REFERENCES}

Bartlett WP, Banker GA (1984) An electron microscopic study of the development of axons and dendrites by hippocampal neurons in culture. II. Synaptic relationships. J Neurosci 4:1954-1965.

Begovac PC, Shur BD (1990) Cell surface galactosyltransferase mediates the initiation of neurite outgrowth from PC12 cells on laminin. J Cell Biol 110:461-470.

Bonatti S, Torrisi MR (1993) The intermediate compartment between endoplasmic reticulum and Golgi complex in mammalian cells. In: The endoplasmic reticulum. Subcellular biochemistry 21 (Borgese N, Harris JR, eds), pp 121-142. New York: Plenum.

Bottenstein JE, Sato GH (1979) Growth of a rat neuroblastoma cell line in serum-free supplemented medium. Proc Natl Acad Sci USA 76:514-519.

Broadwell RD, Cataldo AM (1983) The neuronal endoplasmic reticulum: its cytochemistry and contribution to the endomembrane system. J Histochem Cytochem 31:1077-1088.

Cáceres A, Banker G, Steward O, Binder L, Payne M (1984) MAP2 is localized to the dendrites of hippocampal neurons which develop in culture. Dev Brain Res 13:314-318.

De Camilli P, Moretti M, Denis Donini S, Walter U, Lohmann S (1986) Heterogeneous distribution of the cAMP receptor protein RII in the nervous system. J Cell Biol 103:189-203.

Dong DL, Xu ZS, Chevrier MR, Cotter RJ, Cleveland DW, Hart GW (1993) Glycosylation of mammalian neurofilaments. Localization of multiple O-linked $\mathrm{N}$-acetylglucosamine moieties on neurofilament polypeptides L and M. J Biol Chem 268:16679-16687.

Eckstein DJ, Shur BD (1989) Laminin induces the stable expression of surface galactosyltransferase on lamellipodia of migrating cells. J Cell Biol 108:2507-2517.
Elbein AD (1991) Glycosidase inhibitors: inhibitors of N-linked oligosaccharide processing. FASEB J 5:3055-3063.

Furuichi T, Simon-Chazottes D, Fujino I, Yamada N, Hasegawa M, Miyawaki A, Yoshikawa S, Guénet J-L, Mikoshiba K (1993) Widespread expression of inositol 1.4.5-triphosphate receptor type 1 gene (Insp3r1) in the mouse central nervous system. Receptors Channels $1: 11-24$.

Gething M-J, Sambrook J (1992) Protein folding in the cell. Nature 355:33-45.

Gonatas JO, Mezitis SGE, Stieber A, Fleicher B, Gonatas NK (1989) A novel sialoglycoprotein of the medial cisternae of the Golgi apparatus. J Biol Chem 264:646-653.

Haltiwanger RS, Kelly WG, Roquemore EP, Blomberg MA, Dong L-YD, Kreppel L, Chou TY, Hart GW (1992) Glycosylation of nuclear and cytoplasmic proteins is ubiquitous and dynamic. Biochem Soc Trans 20:264-269.

Hammerschlag R, Stone GC, Bolen FA, Lindsey JD (1982) Evidence that all newly synthesized proteins destined for fast axonal transport pass through the Golgi apparatus. J Cell Biol 93:568-575.

Hammond C, Braakman I, Helenius A (1994) Role of N-linked oligosaccharide recognition, glucose trimming, and calnexin in glycoprotein folding and quality control. Proc Natl Acad Sci USA 91:913-917.

Hilwig I, Grop A (1975) pH-dependent fluorescence of DNA and RNA in cytologic staining with "Hoechst 33258." Exp Cell Res 91:457-460.

Hortsch M, Meyer DL (1985) Immunochemical analysis of rough and smooth microsomes from rat liver. Segregation of docking protein in rough membranes. Eur J Biochem 150:559-564.

Kleiman R, Banker GA, Steward O (1990) Differential subcellular localization of particular mRNAs in hippocampal neurons in culture. Neuron 5:821-830.

Kleiman R, Banker G, Steward O (1993) Subcellular distribution of rRNA and poly(A) RNA in hippocampal neurons in culture. Mol Brain Res 20:305-312.

Kornfeld R, Kornfeld S (1985) Assembly of asparagine-linked oligosaccharides. Annu Rev Biochem 54:631-664.

Krijnse-Locker J, Parton RG, Fuller SD, Griffiths G, Dotti CG (1995) The organization of the endoplasmic reticulum and the intermediate compartment in cultured rat hippocampal neurons. Mol Biol Cell 6:1315-1332.

Kuismanen E, Saraste J (1989) Low temperature-induced transport blocks as tools to manipulate membrane traffic. Methods Cell Biol 32:257-274.

Lippincott Schwartz J, Yuan LC, Bonifacino JS, Klausner RD (1989) Rapid redistribution of Golgi proteins into the ER in cells treated with Brefeldin A: evidence for membrane cycling from Golgi to ER. Cell 56:801-813.

Lopez LC, Maillet CM, Oleszkowicz K, Shur BD (1989) Cell surface and Golgi pools of $\beta 1.4$-galactosyltransferase are differentially regulated during embryonal carcinoma cell differentiation. Mol Cell Biol 9:2370-2377.

Lowenstein PR, Morrison EE, Bain D, Shering AF, Banting G, Douglas P, Castro MG (1994) Polarized distribution of the trans-Golgi network marker TGN38 during the in vitro development of neocortical neurons: effects of Nocodazole and Brefeldin A. Eur J Neurosci 6:1453-1465.

Luzio JP, Brake B, Banting G, Howell KE, Braghetta P, Stanley KK (1990) TGN 38: Identification, sequencing and expression of an integral membrane protein of the trans-Golgi network. Biochem J 270:97-102.

Martone ME, Zhang Y, Simpliciano V, Carragher BO, Ellisman MH (1993) Three-dimensional visualization of the smooth endoplasmic reticulum in Purkinje cell dendrites. J Neurosci 13:4636-4646.

McLean I, Nakane PK (1974) Periodate-lysine paraformaldehyde fixative. A new fixative for immunoelectron microscopy. J Histochem Cytochem 22:1077-1083.

Miyashiro K, Dichter M, Eberwine J (1994) On the nature and differential distribution of mRNAs in hippocampal neurites: implications for neuronal functioning. Proc Natl Acad Sci USA 91:10766-10768.

Moremen KW, Touster O (1986) Topology of mannosidase II in rat liver Golgi membranes and release of the catalytic domain by selective proteolysis. J Biol Chem 261:10945-10951.

Moremen KW, Touster O, Robins PW (1991) Novel purification of the catalytic domain of Golgi $\alpha$-mannosidase II: characterization and comparison with the intact enzyme. J Biol Chem 266:16876-16885.

Morré DJ, Kartenbeck J, Franke W (1979) Membrane flow and interconversions among endomembranes. Biochim Biophys Acta 559:71-152. 
Rao A, Steward O (1991) Evidence that protein constituents of postsynaptic membrane specializations are locally synthesized: analysis of proteins synthesized within synaptosomes. J Neurosci 11:2881-2995.

Saraste J, Svensson K (1991) Distribution of the intermediate elements operating in ER to Golgi transport. J Cell Sci 100:415-430.

Shur B (1989) Expression and function of cell surface galactosyltransferase. Biochim Biophys Acta 988:389-409.

Spacek J (1985) Three-dimensional analysis of dendritic spines. II. Spine apparatus and other cytoplasmic components. Anat Embryol 171:235-243.

Steward O (1995) Targeting of mRNAs to subsynaptic microdomains in dendrites. Curr Opin Neurobiol 5:55-61.

Steward O, Levy WB (1982) Preferential localization of polyribosomes under the base of dendritic spines in granule cells of the dentate gyrus. J Neurosci 2:284-291.

Steward O, Reeves TM (1988) Protein synthetic machinery beneath postsynaptic sites on CNS neurons: association between polyribosomes and other organelles at the synaptic site. J Neurosci 8:176-184.

Steward O, Ribak CE (1986) Polyribosomes associated with synaptic specializations on axon initial segments: localization of proteinsynthetic machinery at inhibitory synapses. J Neurosci 6:3079-3085.

Suzuki (1963) The pattern of mammalian brain gangliosides. II. Evaluation of the extraction procedures, postmortem changes, and the effect of formalin preservation. J Neurochem 12:629-638.
Takei K, Stukembrok H, Metcalf A, Mignery GA, Südhof TC, Volpe P, Camilli PD (1992) $\mathrm{Ca}^{+}$stores in Purkinje neurons: endoplasmic reticulum subcompartments demonstrated by heterogeneous distribution of $\mathrm{Insp}_{3}$ receptor, $\mathrm{Ca}^{2+}$-ATPase, and Calsequestrin. J Neurosci 12:489-505.

Terasaki M, Slater NT, Fein A, Schmidek A, Reese TS (1994) Continuous network of endoplasmic reticulum in cerebellar Purkinje neurons. Proc Natl Acad Sci USA 91:7510-7514.

Torre ER, Steward O (1992) Demonstration of local protein synthesis within dendrites using a new culture system that permits the isolation of living axons and dendrites from their cell bodies. J Neurosci 12:762-772.

Torre ER, Steward O (1993) Post translational modifications of proteins within dendrites: evaluation of sugar incorporation in isolated dendrites from neurons in culture. Soc Neurosci Abstr 19:63.

Torre ER, Steward O (1995) Immunochemical localization of the Golgi apparatus (GA) within dendrites of hippocampal neurons in culture and in situ. Mol Biol Cell [Suppl] 6:100a.

Varki A, Freeze HH (1994) The major glycosylation pathways of mammalian membranes. A summary. Subcell Biochem 22:71-100.

Villa A, Sharp AH, Racchetti G, Podini P, Bole DG, Dunn WA, Pozzan T, Snyder SH, Meldolesi J (1992) The endoplasmic reticulum of Purkinje neuron body and dendrites: molecular identity and specializations for $\mathrm{Ca}^{2+}$. Neuroscience 49:467-477. 